\title{
Plazma Ortamında Aktifleştirilen Bimetalik Nano-katalizör Varlığında Sodyum Borhidrürün Hidrolizinin İncelenmesi
}

\author{
Tülin Avcı Hansu*1, Saliha Özarslan² \\ ${ }^{1}$ Siirt Üniversitesi, Mühendislik Fakültesi, Kimya Mühendisliği Bölümü, Siirt, Türkiye, (ORCID: 0000-0001-5441-4696), tulin.hansu@siirt.edu.tr \\ ${ }^{2}$ Erciyes Üniversitesi, Mühendislik Fakültesi, Makine Mühendisliği Bölümü, Kayseri, Türkiye, (ORCID: 0000-0001-5696-9644), salihaozarslan@windowslive.com
}

(İlk Geliş Tarihi 13 Ekim 2021 ve Kabul Tarihi 20 Aralık 20212)

(DOI: 10.31590/ejosat.1008996)

\begin{abstract}
ATIF/REFERENCE: Avcı Hansu, T. \& Özarslan, S. (2021). Plazma Ortamında Aktifleştirilen Bimetalik Nano-katalizör Varlığında Sodyum Borhidrürün Hidrolizinin İncelenmesi. Avrupa Bilim ve Teknoloji Dergisi, (31), 487-492.

Öz

$\mathrm{Bu}$ çalışmada $\mathrm{CoBi}$ bimetalik nano katalizörüne plazma etkisi ile hidroliz reaksiyonundaki aktivitesi araştırılmıştır. Hidrojen kaynağı olarak sodyum borhidrür kullanılmıştır. Sentezlenen katalizörün yüzeyi geçirmeli elektron mikroskopisi (TEM) ve yüzey boyut dağılımı (BET) ile analiz edilmiştir. Plazma etkisini incelemek için katalizör plazma gücü (\%60, \%80 ve \%100), plazma süresi (10, 15 ve 20 dakika) ve plazma ortamına verilen inert gaz $\left(\mathrm{CO}_{2}, \mathrm{~N}_{2}\right.$ ve Ar) gibi çeşitli parametreler uygulanmıştır. Bu uygulanan parametreler sonucu oluşan katalizör, $30{ }^{\circ} \mathrm{C}, 10 \mathrm{ml} \mathrm{su}, \% 1 \mathrm{NaBH}_{4}, \% 5 \mathrm{NaOH}$ ve $25 \mathrm{mg}$ katalizör varlığında hidroliz reaksiyonuna ilave edilmiştir. Hidroliz reaksiyonunu tamamlama süreleri referans alınarak CoBi katalizörünü aktifleştirmek için uygun koşulların $\mathrm{CO}_{2}$ gazı ortamında $\% 80$ plazma gücü ile 15 dakika plazma uygulanması olduğu belirlenmiştir
\end{abstract}

Anahtar Kelimeler: Plazma etkisi, Nano-katalizör, Hidrojen üretimi, Sodyum borhidrür.

\section{Investigation of Hydrolysis of Sodium Borohydride in the Presence of Activated Bimetallic Nano-catalyst in Plasma Medium}

\begin{abstract}
The activity of a CoBi bimetallic nanocatalyst in a hydrolysis reaction with a plasma effect was investigated in this study. Sodium borohydride was used as the hydrogen source. The surface of the synthesized catalyst was analyzed by transmission electron microscopy (TEM) and surface size distribution (BET). Various parameters such as catalyst plasma power $(60 \%, 80 \%$ and $100 \%)$, plasma time (10, 15 and $20 \mathrm{~min})$ and inert gas $\left(\mathrm{CO}_{2}, \mathrm{~N}_{2}\right.$ and $\mathrm{Ar}$ ) given to the plasma medium were applied to examine the plasma effect. The catalyst produced by these parameters was added to the hydrolysis reaction in the presence of $30{ }^{\circ} \mathrm{C}, 10 \mathrm{ml}$ of water, $1 \%$ $\mathrm{NaBH}_{4}, 5 \% \mathrm{NaOH}$, and $25 \mathrm{mg}$ of catalyst. Based on the hydrolysis reaction completion times, it was determined that the best conditions for activating the $\mathrm{CoBi}$ catalyst were to apply plasma for 15 minutes at $80 \%$ plasma power in a $\mathrm{CO}_{2}$ gas environment.
\end{abstract}

Keywords: Plasma effect, Nano-catalyst, Hydrogen production, Sodium borohydride.

"Sorumlu Yazar: tulin.hansu@siirt.edu.tr, tulinn_avci@hotmail.com 


\section{Giriş}

Yenilenebilir enerji; güneş, rüzgar, dalga, okyanus 1sıs1, jeotermal, gelgit ve biyokütle gibi çok çeşitli kaynaklardan elde edilebilen temiz ve tükenmeyen bir enerji çeşididir. Dolayısıyla yenilenebilir enerji, tükenme tehlikesi ile karşı karşıya olan fosil kaynakların yerine kullanılabilecek güçlü bir adaydır. Fosil yakıtlar; hava kirliliği, iklim değişikliği, sera gazı etkisi gibi yaşamı tehdit altına alan olumsuz etkileriyle bilinmektedir (ATELGE), (ATELGE, 2021).Yenilenebilir enerji kaynaklarının fosil yakıtların yerini alması ile bu gibi zararlı etkilerin en aza indirileceği ve gelecek nesillere daha yaşanabilir bir dünya bırakılabileceği öngörülmektedir (Moriarty \& Honnery, 2020). Yenilenebilir enerji sistemlerinin geliştirilmesi; enerji tedarik güvenilirliğinin ve organik yakıt ekonomisinin iyileştirilmesi, nüfusun yaşam standardının ve istihdam düzeyinin artırılması, çöl ve dağlık bölgelerin kalkınmasının sağlanması, kırsal kesimde iş firsatları yaratılarak kentsel alanlara göçün en aza indirilmesi gibi avantajları da bünyesinde barındırmaktadır (Panwar, Kaushik, \& Kothari, 2011).

Yenilenebilir enerji kaynakları, farklı yöntemler kullanılarak elektrik ve çeşitli formlarda yakıtlar gibi diğer enerji biçimlerine dönüştürülebilir. Örneğin güneş enerjisi doğrudan su ve alan 1sıtma amaçlı kullanılabileceği gibi elektrik üretiminde de kullanılabilir. Bir diğer yenilenebilir enerji kaynağı olan biyokütle, gelişmekte olan ülkelerde enerji arzı üzerinde çok önemli bir etkiye sahiptir. Biyokütle kaynakları, binalarda 1sı ve 1şık sağlamada, elektrik üretiminde ve katı, sıvı veya gaz yakıtlara dönüştürülerek kullanılabilir (Xia \& Xia, 2010). Enerji kaynaklarının farklı yöntemler kullanılarak dönüştürüldüğü gaz yakıt türlerinden biri de hidrojendir. Hidrojen, yüksek verimliliği, bolluğu, sıfır emisyonu ve yenilenebilirliği ile en temiz enerji türlerinden biridir. Hidrojen kullanımının yaygınlaştırılması, fosil yakıtların yanması ile oluşan karbon emisyonlarının olumsuz etkisini azaltmak için potansiyel bir yoldur (KARAOĞLU \& KARAOĞLU). Hidrojen, zamana ve kullanım yerine göre talebe ayak uydurmak için birçok biçimde depolanabilir ve kolayca taşınabilir. $\mathrm{Bu}$ nedenle çeşitli endüstriler, evsel kullanımlar, otomotiv uygulamaları ve elektrik üretimi gibi birçok farklı alanda hidrojen kullanımı mümkündür. Hidrojen depolama için fiziksel ve kimyasal olarak tanımlanan iki yöntem kullanılmaktadır. Fiziksel depolama yöntemleri; sıkıştırılmış gaz şeklinde, sıvı halde ve kriyoadsorpsiyon ile depolamadır. Kimyasal depolama yönteminde ise hidrojen molekülleri, kimyasal reaksiyonlar kullanılarak katı bileşiklerde depolanabilir (BOYNUEĞRİ \& Metin, 2021).

Özellikle ulaşım sektöründe hidrojene dayalı bir enerji sistemi kurulması için hidrojen depolama teknolojisinin önemli ölçüde geliştirilmesi gerekmektedir. Kimyasal hidrürlerin hidrojen depolamak için oldukça güvenli ve umut verici bir seçenek olduğuna inanılmaktadır (Shang \& Chen, 2006). Kimyasal hidrürler arasında, sodyum borhidrür $\left(\mathrm{NaBH}_{4}\right)$, yanmazlık, kolay kontrol edilebilen hidrojen üretim hızı, yan ürünün geri dönüştürülebilirliği ve yüksek $\mathrm{H}_{2}$ depolama verimliliği gibi avantajları sayesinde hidrojen depolama malzemesi olarak yoğun bir şekilde çalışılmıştır (Lee et al., 2007; Wee, Lee, \& Kim, 2006). Denklem 1'de $\mathrm{NaBH}_{4}$ hidroliz reaksiyonu verilmiştir. Uygun bir katalizör varlığında, $1 \mathrm{~mol}$ $\mathrm{NaBH}_{4}$ hidroliz reaksiyonunda $4 \mathrm{~mol} \mathrm{H}_{2}$ üretilir. $\mathrm{NaBH}_{4}{ }^{\prime}$ ün hidroliz ve metanoliz reaksiyonunda kullanılan katalizör hidrojen üretim hızını kontrol eder (Ali, Khan, \& Asiri, 2019; Avci Hansu, Caglar, Demir Kivrak, \& Sahin; Kaya, 2020).

$$
\mathrm{NaBH}_{4}+2 \mathrm{H}_{2} \mathrm{O} \rightarrow \mathrm{NaBO}_{2}+4 \mathrm{H}_{2}
$$

$\mathrm{NaBH}_{4}$ 'den hidrojen üretimi ile ilgili literatürde pek çok çalışma vardır. Yapılan literatür araştırmasında $\mathrm{NaBH}_{4}$ 'den hidrojen üretimi konusu halen araştırmacıların dikkatini çekmektedir (Avci Hansu et al.; Avci Hansu, Sahin, Çağlar, \& Demir Kivrak, 2021; Bekirogullari, Abut, Duman, \& Hansu, 2021; T. Hansu, Caglar, Sahin, \& Demir Kıvrak, 2020; T. A. Hansu, Sahin, Caglar, \& Kivrak, 2020; Kaya, 2020).

Co metali katalitik reaksiyonlarda aktif olduğu için bu çalışmada tercih edilmiştir. İkinci metal ilave edilerek sentezlenen katalizörün aktivitesi ve kararlılığı arttırılmak istenmiştir. Çalışmada ikinci metal olarak Bi tercih edilmiş̧ir. Plazma uygulanan katalizörlerin aktivitesinin arttığı birçok çalışmada kanıtlanmıştır (Ekinci, Şahin, Saka, \& Avci, 2013; Mistry et al., 2016; Şahin, Karakaş, Kaya, \& Saka, 2017; Şahin, Saka, Baytar, \& Hansu, 2013). Bundan dolayı bu çalışmada katalizörü aktifleştirmek için plazma yöntemi tercih edilmiş̧ir. Bu çalışmada plazma ortamında aktifleştirilen CoBi 95:5 atomik oranında bimetalik katalizörünün hidrolizi incelenmiştir. $\mathrm{CoBi}$ (95:5) katalizörünün aktifliği plazma ortamında farklı güç yoğunluğu, farklı inert gaz ortamı ve plazma süresi gibi parametrelerle değerlendirildi. Sentezlenen CoBi (95:5) katalizörünün yüzeyi hakkında bilgi almak için TEM ve BET analizi yapıldı.

\section{Materyal ve Metot}

\subsection{Katalizörün Hazırlanması}

İkili alaşım formunda $\mathrm{CoBi}$ katalizörü sentezlenirken öncelikle kobalt nitrat $\left(\mathrm{Co}\left(\mathrm{NO}_{3}\right)_{2} 6 \mathrm{H}_{2} \mathrm{O}\right)$ ve bizmut nitrat $\left(\mathrm{BiO}(\mathrm{OH})_{9}\left(\mathrm{NO}_{3}\right)_{4}\right)$ sulu çözeltileri 95:5 atomik oranında karıştırıldı. Karışım halindeki çözeltinin indirgenmesi güçlü bir karıştırıcı altında ve sodyum borhidrür $\left(\mathrm{NaBH}_{4}\right)$ ile gerçekleştirildi. Fazla miktarda sodyum borhidrür kullanılarak metal katyonların tamamen indirgenmesi sağlandı. İndirgemeden sonra CoBi katalizörü vakum pompası yardımıyla süzüldü ve deiyonize su ve etanol ile yıkandı ve sürekli akışlı $\mathrm{N}_{2}$ ortamında $353 \mathrm{~K}$ 'de 3-4 saat boyunca kurutulmaya birakıld1. Kurutulan CoBi (95:5) katalizörünün oksitlenmemesi için kapalı ortamda muhafaza edilerek deneysel çalışmalarda kullanıma hazır hale getirildi.

\subsection{Plazma Etkisi}

CoBi (95:5) katalizörünü plazma ile aktifleştirmek için 100 $\mathrm{mm}$ çapında ve $270 \mathrm{~mm}$ uzunluğunda, $2.5 \mathrm{~Pa}$ basınçta ve $80 \mathrm{~W}$ güç girişinde bir hazneye sahip bir plazmokimyasal reaktör (Femto, Diener electronic, Almanya) kullanıldı. Katalizör tozu (yaklaşık 0,5 g) bir kuvars tekneye yüklendi ve boşaltma hücresine konuldu. Katalizör numunesi reaktöre konuldu ve istenilen plazma gücü, süresi ve inert gaz ortamında plazmaya tabi tutuldu. Elde edilen katalizörler, daha sonra kullanılmak üzere hava geçirmez numune kabında saklandı. Şekil 1'de çalışmada kullanılan sistem şematik olarak gösterilmiştir 


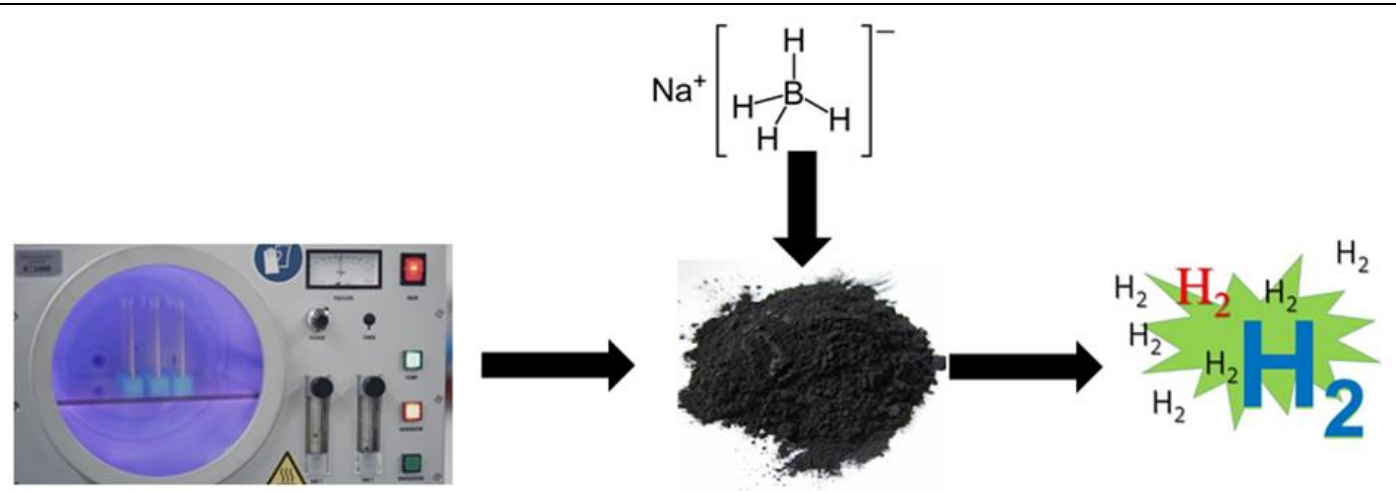

$\mathrm{CO}_{2}$ gazı ortamında $\% 80$ plazm a gücü ile $15 \mathrm{dk}$ plazma etkisi

Şekil 1. Kullanılan Sistemin Şematik Gösterimi

\subsection{Yüzey Karakterizasyonu}

CoBi nanoparçacığının morfolojisi ve boyut dağılımları Zeiss Sigma 300 transmisyon elektron mikroskobu (TEM) ile karakterize edildi. Yüzey yapısı Brunauer-Emmett-Teller (BET) yöntemini kullanan yüzey alanı ve gözeneklilik ölçüm analizörü ile donatılmış bir Micromeritics Tristar II 3020 üzerinde gerçekleştirilmiştir.

\section{Araștırma Sonuçları ve Tartışma}

\subsection{Yüzey Karakterizasyonu Sonuçları}

Geçirmeli elektron mikroskopisi (TEM) partiküllerin şeklini ve boyutunu belirlemede oldukça doğru sonuçlar veren bir tekniktir. Aynı zamanda katının bileşimi ve partiküllerin içyapısı ile ilgili de bilgi sağlamaktadır Sentezleme yönteminde indirgeme işleminin hızlı bir şekilde gerçekleşmesinden dolayı küçük bir yığın gözlenirken, homojen parçacık dağılımı şekilden görülmektedir. Ortalama parçacık boyutu CoBi (95:5) katalizörü için $20 \mathrm{~nm}$ olarak bulundu. CoBi katalizörünün farklı partikül boyutları için oluşturulmuş olan ve histogram grafiklerini de içeren TEM görüntüleri Şekil 2'de verilmiştir.
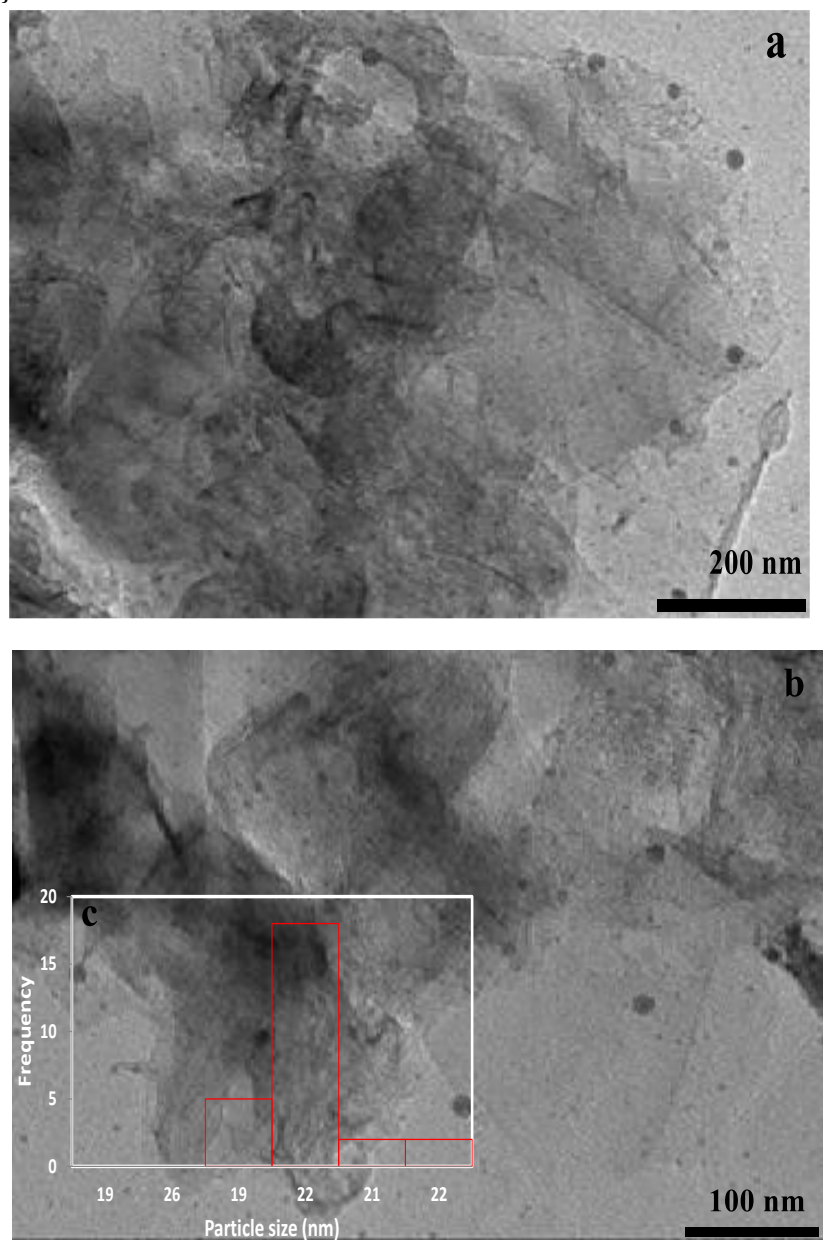

Şekil 2. CoBi Katalizörü (a) $200 \mathrm{~nm}$ Partikül Boyut (b) $100 \mathrm{~nm}$ Partikül Boyut (c) 100 nm Partikül Boyut Histogram Grafik İnsert

Sentezlenen katalizör mezopöz yapısını gösteren $\mathrm{V}$ tipi adsorpsiyon izotermini sergiler. CoBi (95:5) katalizörünün BET yüzey alanı $16.9711 \mathrm{~m}^{2} / \mathrm{g}$ olarak hesaplandı ve bu değerler Tablo 1 'de verilmiştir. BJH ile hesaplanan CoBi katalizörünün gözenek büyüklüğü $18.1127 \mathrm{~nm}$ olarak bulundu. CoBi katalizörünün BET yüzey alanı, gözenek hacmi ve gözenek boyutu Tablo 1'de verilmiştir. TEM'de hesaplanan gözenek boyutunun $20 \mathrm{~nm}$ olması BET analizinde hesaplanan gözenek boyutuna çok yakın olduğundan katalizör içeriğinde homojen bir dağılım ve sentezin gerçekleştiğini söyleyebiliriz. 


\begin{tabular}{llll}
\hline Katalizör & BET Yüzey & Gözenek Hacmi (cc/g) & Gözenek Boyutu (nm) \\
& Alanı $\left(\mathbf{m}^{2} / \mathbf{g}\right)$ & \\
\hline CoBi $(\mathbf{9 5 : 5 )}$ & 16.9711 & 0.078029 & 18.1127 \\
\hline
\end{tabular}

\subsection{Hidroliz Deneyleri}

\subsubsection{Farklı Inert Gaz Ortamının Hidrojen Üretimine Etkisi}

Sentezlenen CoBi (95:5) katalizörüne plazma ortamında farklı inert gaz ortamında $\% 80$ plazma gücü 10 dakika uygulandı. $\% 80$ plazma gücü ile 15 dakika plazma uygulanan katalizörlerin $\% 5$ $\mathrm{NaOH}, 10 \mathrm{ml} \% 1^{\prime}$ lik $\mathrm{NaBH}_{4}$ çözeltisi, $30{ }^{\circ} \mathrm{C}$ 'de ve $25 \mathrm{mg} \mathrm{CoBi}$ katalizör varlığında hidroliz reaksiyonları incelenmiştir. Elde edilen hidrojen hacmine bağlı zaman grafikleri Şekil 3'te verilmiştir. Şekilde görüldüğü üzere $\mathrm{CO}_{2}$ gazı ortamında plazma gücü uygulanan katalizör hidroliz reaksiyonunu diğer gaz ortamları ve plazma uygulanmamış haline göre daha kısa sürede tamamlamaktadir.

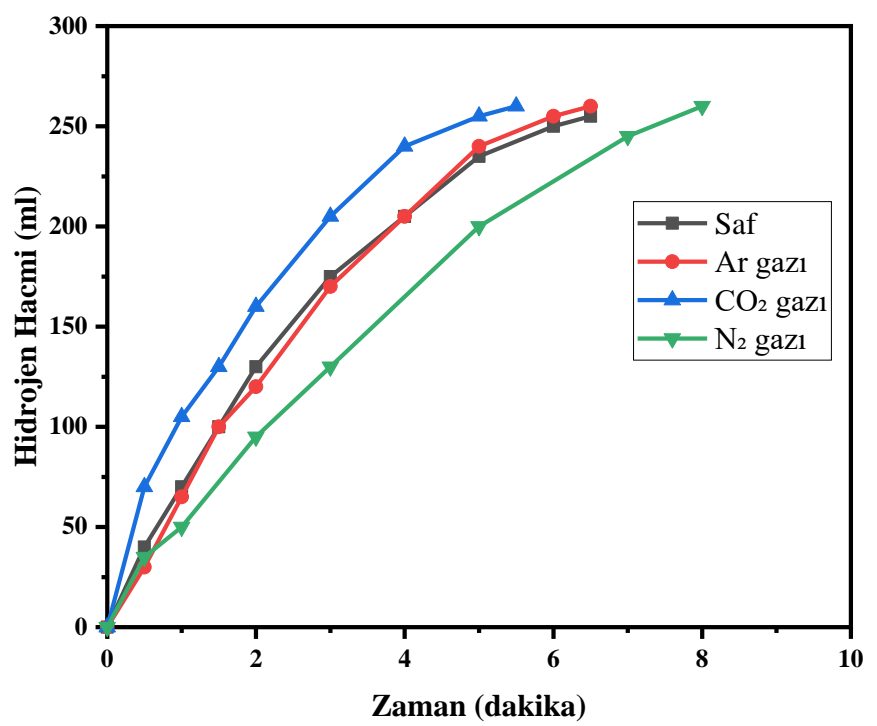

Şekil 3. İnert Gaz Ortamının Hidrojen Üretimine Etkisi ( $\mathrm{T}=30$

${ }^{\circ} \mathrm{C}, \mathrm{V}_{\mathrm{su}}=10 \mathrm{ml}, \% 1 \mathrm{NaBH}_{4}, \% 5 \mathrm{NaOH}, 25 \mathrm{mg}$ katalizör)

\subsubsection{Uygulanan Plazma Süresinin Hidrojen Üretimine Etkisi}

Plazma ortamında $\mathrm{CO}_{2}$ gazına karar verdikten sonra plazma süresinin etkisi incelendi. Plazma süresinin hidrojen üretimine etkisini incelemek için; CoBi (95:5) katalizörüne \%80 plazma gücü ve $\mathrm{CO}_{2}$ gazı ortamında farklı sürelerde $(10,15,20$ dakika) plazma uygulandı. Elde edilen katalizörlerin $30{ }^{\circ} \mathrm{C}, 10 \mathrm{ml} \mathrm{su}, \% 1$ $\mathrm{NaBH}_{4}, \% 5 \mathrm{NaOH}$ ve $\mathrm{CO}_{2}$ gazı ortamında $\% 80$ plazma gücü farklı sürelerde uygulanan $25 \mathrm{mg} \mathrm{CoBi}$ (95:5) katalizörü varlığında hidroliz deneyleri yapıldı. Elde edilen hidrojen hacmine bağlı zaman grafiği Şekil 4'te verilmiştir. Şekilde görüldüğü üzere 15 dakika uygulanan plazma süresi hidroliz reaksiyonunu, plazma uygulanmamış ve diğer uygulanan plazma sürelerine göre daha kısa sürede tamamlamaktadır.

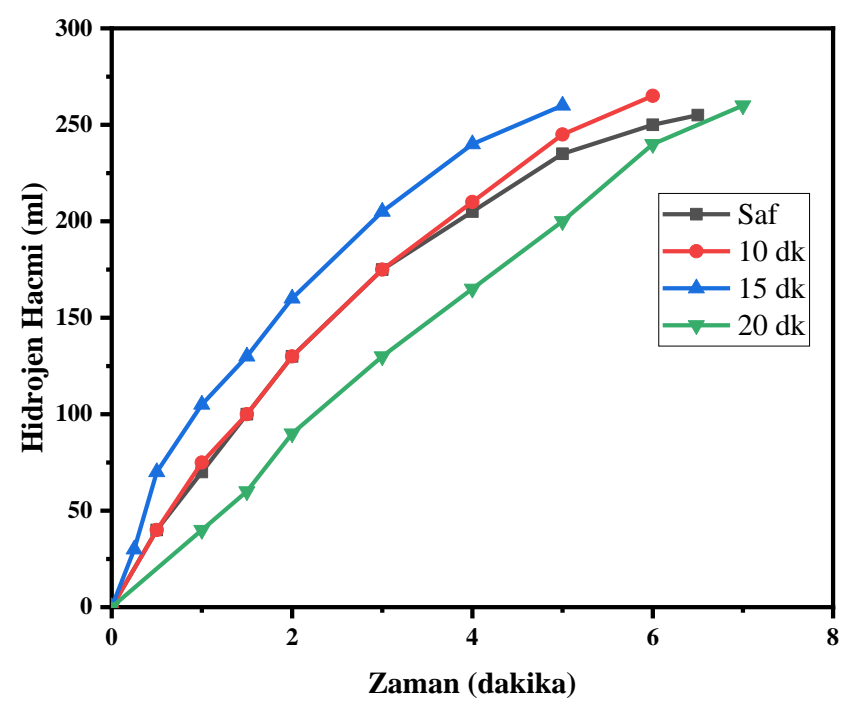

Şekil 4. Uygulanan Plazma Süresinin Hidrojen Üretimine Etkisi $\left(\mathrm{T}=30{ }^{\circ} \mathrm{C}, \mathrm{V}_{\mathrm{su}}=10 \mathrm{ml}, \% 1 \mathrm{NaBH}_{4}, \% 5 \mathrm{NaOH}, 25 \mathrm{mg}\right.$ katalizör)

\subsubsection{Uygulanan Plazma Gücünün Hidrojen Üretimine Etkisi}

Katalizöre uygulanan süre ve inert gaz ortamına karar verildikten sonra uygulanan plazma gücünün hidrojen üretimine etkisi incelendi. Plazma gücünün hidrojen üretimine etkisini incelemek için, $30{ }^{\circ} \mathrm{C}, 10 \mathrm{ml} \mathrm{su}, \% 1 \mathrm{NaBH}_{4}, \% 5 \mathrm{NaOH}$ ve $\mathrm{CO}_{2}$ gazı ortamında 15 dakika farklı plazma gücü uygulanmış $25 \mathrm{mg}$ CoBi (95:5) katalizörü varlığında hidroliz deneyleri yapıldı. Elde edilen hidrojen üretimine bağlı zaman grafiği Şekil 5'te verilmiştir. Şekilde görüldüğü üzere plazma gücü $\% 60^{`}$ tan \%80‘e çıkarıldığında katalizörün hidroliz reaksiyonunu tamamlama süresi kısalmaktadır. Fakat uygulanan plazma gücü \%100'e çıkarıldığında reaksiyonu tamamlama süresi \%80'e göre artmaktadır. Bunun temel nedeni aşırı güç uygulandığında katalizörün aktif yüzeylerinin bozulması ya da zehirlenmesidir. Bundan dolayı katalizör aktivitesini yitirmektedir. 


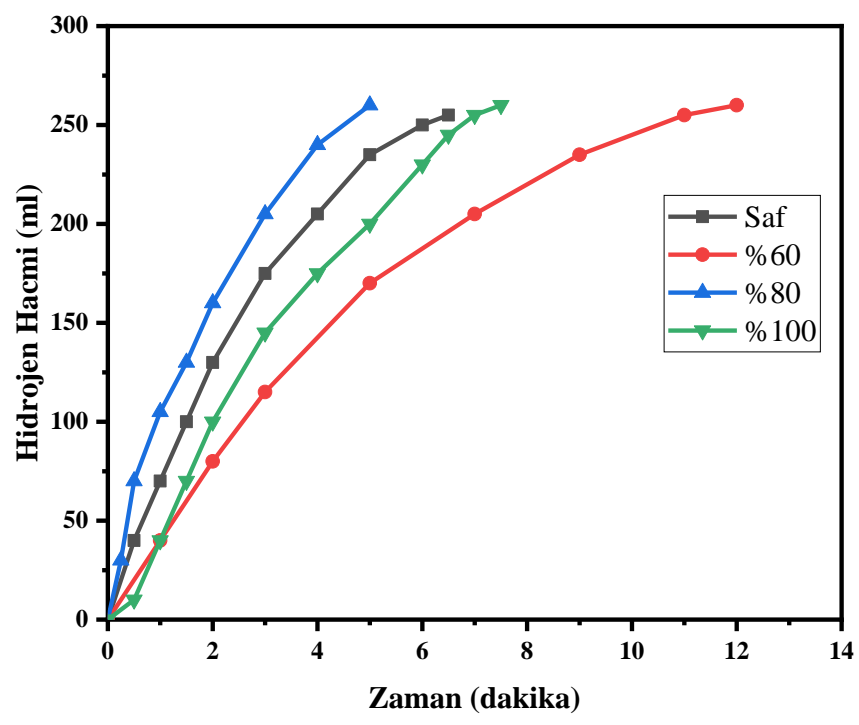

Şekil 5. Uygulanan Plazma Gücünün Hidrojen Üretimine Etkisi $\left(\mathrm{T}=30{ }^{\circ} \mathrm{C}, \mathrm{V}_{\mathrm{su}}=10 \mathrm{ml}, \% 1 \mathrm{NaBH}_{4}, \% 5 \mathrm{NaOH}, 25 \mathrm{mg}\right.$ katalizör $)$

\section{Sonuç}

Günümüzde gelişmiş ve gelişmekte olan ülkelerin en önemli ihtiyacı enerjidir. Bu nedenle yeni ve yenilenebilir enerji kaynakları ile ilgili çalışmalar ve araştırmalar sınırlı kaynaklara sahip fosil yakıtlara alternatif olması açısından oldukça önemlidir. Bu durumda hidrojen enerjisi devreye girer. Hidrojen, kullanıldığı teknolojilerde verimliliği artırması ve kirletici etkilerinin düşük olması nedeniyle gelecekte dikkate alınması gereken en önemli enerji kaynağı olarak görülmektedir

$\mathrm{Bu}$ çalışmada literatürde optimum hidrojen üretim şartları belirli olan CoBi (95:5) katalizörünün aktifleştirilmesi incelenmiştir. Yapılan deneyler sonucunda $\mathrm{CO}_{2}$ gazı ortamında 15 dakika \%80 plazma gücü $\mathrm{CoBi}$ (95:5) katalizörüne uygulandığında hidrojen üretim verimliliği saf haline göre artmıştır. Plazma uygulanmayan katalizör hidroliz reaksiyonunu 6,5 dakikada tamamlarken belirlenen koşullarda plazma uygulanan katalizör hidroliz reaksiyonunu 4,5 dakika gibi daha kısa sürede tamamlamıştır. Bilindiği üzere kimyasal proseslerde süreç ne kadar hızlı ilerlerse istenen ürün ve verim o derecede artmaktadır. Bu sonuçlar ışığında çalışma amacına ulaşmıştır. . Üretilen katalizöre destek malzemesi eklenerek daha aktif ve daha karalı bir katalizör tasarlanıp sentezlenebilir. Bu çalışma bu yönü ile diğer çalışmalara öncülük etmektedir.

\section{Kaynakça}

Ali, F., Khan, S. B., \& Asiri, A. M. (2019). Chitosan coated cellulose cotton fibers as catalyst for the $\mathrm{H} 2$ production from $\mathrm{NaBH} 4$ methanolysis. international journal of hydrogen energy, 44(8), 4143-4155.

ATELGE, R. Kısmi Yük Koşullarında Dizel-Biyogaz Kullanılarak Çift Yakıtlı Dizel Motorun Enerji ve Ekserji Analizi. Avrupa Bilim ve Teknoloji Dergisi(27), 334-346.

ATELGE, R. (2021). Türkiye'de Sığır Gübresinden Biyoyakıt Olarak Biyogaz Üretiminin Potansiyeli ve 2030 ve 2053 Yıllarında Karbon Emisyonlarının Azaltılmasına Öngörülen Etkisi. International Journal of Innovative Engineering Applications, 5(1), 56-64.
Avci Hansu, T., Caglar, A., Demir Kivrak, H., \& Sahin, O. Structure of ruthenium nanocatalysts of bismuth, investigation of its effect on hydrolysis performance and kinetic studies. Energy Storage, e267.

Avci Hansu, T., Sahin, O., Çağlar, A., \& Demir Kivrak, H. (2021). Untangling the cobalt promotion role for ruthenium in sodium borohydride dehydrogenation with multiwalled carbon nanotube-supported binary ruthenium cobalt catalyst. International Journal of Energy Research, 45(4), 60546066.

Bekirogullari, M., Abut, S., Duman, F., \& Hansu, T. A. (2021). Lake sediment based catalyst for hydrogen generation via methanolysis of sodium borohydride: an optimization study with artificial neural network modelling. Reaction Kinetics, Mechanisms and Catalysis, 1-18.

BOYNUEĞRİ, T. A., \& Metin, G. (2021). RELEASING HYDROGEN FROM NABH4 VIA HYDROGEL BASED CoF2 CATALYST. Isı Bilimi ve Tekniği Dergisi, 41(1), 1-9.

Ekinci, A., Şahin, Ö., Saka, C., \& Avci, T. (2013). The effects of plasma treatment on electrochemical activity of $\mathrm{Co}-\mathrm{W}-\mathrm{B}$ catalyst for hydrogen production by hydrolysis of $\mathrm{NaBH} 4$. International journal of hydrogen energy, 38(35), 1529515301.

Hansu, T., Caglar, A., Sahin, O., \& Demir Kıvrak, H. (2020). A COMPARATIVE STUDY FOR SODIUM BOROHYDRIDE DEHYDROGENATION AND ELECTROOXIDATION ON CERIUM AND COBALT CATALYSTS.

Hansu, T. A., Sahin, O., Caglar, A., \& Kivrak, H. (2020). A remarkable Mo doped $\mathrm{Ru}$ catalyst for hydrogen generation from sodium borohydride: the effect of Mo addition and estimation of kinetic parameters. Reaction Kinetics, Mechanisms and Catalysis, 131(2), 661-676.

KARAOĞLU, S. Y., \& KARAOĞLU, S. HYDROGEN GENERATION FROM SODIUM BOROHYDRIDE WITH COBALT BORIDE CATALYSTS. ALKÜ Fen Bilimleri Dergisi, 2(2), 84-96.

Kaya, M. (2020). Production of metal-free catalyst from defatted spent coffee ground for hydrogen generation by sodium borohyride methanolysis. International journal of hydrogen energy, 45(23), 12731-12742.

Lee, J., Kong, K. Y., Jung, C. R., Cho, E., Yoon, S. P., Han, J., . . . Nam, S. W. (2007). A structured Co-B catalyst for hydrogen extraction from $\mathrm{NaBH} 4$ solution. Catalysis today, 120(3-4), 305-310.

Mistry, H., Varela, A. S., Bonifacio, C. S., Zegkinoglou, I., Sinev, I., Choi, Y.-W., . . . Strasser, P. (2016). Highly selective plasma-activated copper catalysts for carbon dioxide reduction to ethylene. Nature communications, 7(1), $1-9$.

Moriarty, P., \& Honnery, D. (2020). Feasibility of a $100 \%$ global renewable energy system. Energies, 13(21), 5543.

Panwar, N., Kaushik, S., \& Kothari, S. (2011). Role of renewable energy sources in environmental protection: A review. Renewable and sustainable energy reviews, 15(3), 1513-1524.

Shang, Y., \& Chen, R. (2006). Hydrogen storage via the hydrolysis of $\mathrm{NaBH} 4$ basic solution: optimization of $\mathrm{NaBH} 4$ concentration. Energy \& fuels, 20(5), 2142-2148.

Şahin, Ö., Karakaş, D. E., Kaya, M., \& Saka, C. (2017). The effects of plasma treatment on electrochemical activity of Co-B-P catalyst for hydrogen production by hydrolysis of $\mathrm{NaBH} 4$. Journal of the Energy Institute, 90(3), 466-475. 
Şahin, Ö., Saka, C., Baytar, O., \& Hansu, F. (2013). Influence of plasma treatment on electrochemical activity of $\mathrm{Ni}$ (o)-based catalyst for hydrogen production by hydrolysis of $\mathrm{NaBH} 4$. Journal of Power Sources, 240, 729-735.

Wee, J.-H., Lee, K.-Y., \& Kim, S. H. (2006). Sodium borohydride as the hydrogen supplier for proton exchange membrane fuel cell systems. Fuel processing technology, 87(9), 811-819.

Xia, X., \& Xia, J. (2010). Evaluation of potential for developing renewable sources of energy to facilitate development in developing countries. Paper presented at the 2010 AsiaPacific Power and Energy Engineering Conference. 